\title{
Cultivo hidropônico de alface com água salobra subterrânea e rejeito da dessalinização em Ibimirim, $\mathrm{PE}^{1}$
}

\author{
Alexandre N. Santos ${ }^{2}$, Tales M. Soares ${ }^{3}$, Ênio F. F. Silva², D avid. J. R. Silva² \& Abelardo A. A. Montenegro
}

\section{RESU MO}

0 M unicípio de Ibimirim, em Pernambuco, está localizado no Semiárido e muitos de seus poços fornecem águas salobras, cujo uso tem sido evitado, em virtude de ensejar doenças humanas (como hipertensão e cálculos renais) e a redução da produtividade agrícola (com depreciação do solo). Propôs-se, no trabalho, avaliar o aproveitamento da água salobra subterrânea e do rejeito da sua dessalinização no cultivo hidropônico de duas variedades de alface (Vera e AF-1743). Avaliaram-se seis níveis de salinidade da água (CEa: $0.2 ; 1.2 ; 2.2 ; 3.2 ; 4.2$ e $5.2 \mathrm{dS} \mathrm{m}^{-1}$ ). As águas foram usadas em todo o processo produtivo (preparo da solução nutritiva e reposição do consumo hídrico). 0 aumento da salinidade levou à redução linear do crescimento das plantas de alface. As plantas apresentaram clorose generalizada no início do ciclo mas este sintoma não foi detectado na colheita. A variedade 'Vera' teve menor crescimento e rendimento absoluto que a 'AF-1743'. Por outro lado, para ambas as variedades a redução percentual em função da salinidade foi equivalente: 0 acúmulo de massa fresca da parte aérea foi reduzido à razão de 17,06 e 15,74\% (dS m-1 $)^{-1}$ para 'Vera' e 'AF-1743', respectivamente.

Palavras-chave: salinidade, cultivo sem solo, hortaliças, osmose reversa, irrigação

\section{Hydroponic lettuce production with brackish groundwater and desalination waste in Ibimirim, PE, Brazil}

\begin{abstract}
Ibimirim in Pernambuco is a municipal district located in the Brazilian semiarid region and most of its wells produce brackish water. The use of this water has been avoided since it may cause human diseases (such as hypertension and kidney stones) and crop yield reduction (with soil degradation). The objective of this work was to evaluate the utilization of brackish groundwater and the waste from its desalination for hydroponic production of two lettuce varieties (Vera and AF-1743). Six levels of water salinity (CEa: $0.2,1.2,2.2,3.2,4.2$ and $5.2 \mathrm{dS} \mathrm{m}^{-1}$ ) were analyzed. The waters were used in overall production process (to prepare the nutrient solution and to restore the water consumed). The salinity increase caused a linear reduction in the growth lettuce of plants. The plants exhibited general chlorosis at the beginning of the cycle, but this symptom was not verified at the harvest. The variety 'Vera' had a lower absolute growth and yield than the 'AF-1743'. On the other hand, the percent reduction for both varieties was similar - the shoot fresh matter accumulation was decreased by 17.06 and $15.74 \%\left(\mathrm{dS} \mathrm{m}^{-1}\right)^{-1}$ for 'Vera' and 'AF-1743', respectively.
\end{abstract}

Key words: salinity, soilless, vegetables, reverse osmosis, irrigation

\footnotetext{
1 Parte da dissertação de mestrado do primeiro autor, ap resentada ao Programa de Pós-G raduação em Engenharia Agrícola da Universidade Federal Rural de Pernambuco 2 DTR/UFRPE, Rua Dom Manoel de Medeiros s/n, Dois Irmãos. CEP 52171-900, Recife, PE. Fone: (81) 3320-6279. E-mail: alexandrens14@yahoo.com.br; talesmiler@gmail.com; enio.silva@dtr.ufrpe.br; david_james@ig.com.br; abelardo.montenegro@yahoo.com.br

3 CCAAB/UFRB, Campus de Cruz das Almas, CEP 44380-000, Cruz das Almas, BA. Fone: (75) 3621-2798. E-mail: talesmiler@gmail.com
} 


\section{INTRODUÇÃO}

No semiárido a irregularidade e as baixas taxas de precipitação pluvial, aliadas às elevadas taxas de evapotranspiração e ao predomínio de rochas impermeáveis (embasamento cristalino), favorecem a escassez de águas superficiais (Costa et al., 2006) e desfavorecem a implantação de sistemas de produção agrícola convencionais em sequeiro. Nesta mesma região existem reservas subterrâneas que poderiam melhorar a relação de convivência com as estiagens prolongadas. Por outro lado, muitos dos poços perfurados possuem baixas vazões e altos teores de sais dissolvidos, restrições que, em parte, explicam o abandono de inúmeros poços públicos e privados (Costa, 1995).

A utilização dessas águas salobras para o uso agrícola pode oferecer riscos ao meio ambiente, promovendo a salinização dos solos e consequente redução da produção agrícola (Beltran, 1999; Porto et al., 2001; Alencar et al., 2003; Garcia et al., 2008). Na dessedentação humana o uso direto dessas águas também tem sido pouco recomendado visto que causam doenças, como hipertensão e cálculos renais (Brasil, 2000).

Uma alternativa encontrada para favorecer a utilização das águas salobras para o consumo humano é a sua dessalinização por osmose reversa. Esta técnica tem sido muito fomentada no Semiárido brasileiro, tornando-se um importante instrumento para melhoria da qualidade de vida dos seus habitantes. Por outro lado, muitos desses aparelhos se encontram desativados, por desconhecimento técnico ou por questões econômicas dos usuários (Pinheiro \& Callado, 2005). A dessalinização produz não só uma água de boa qualidade, mas também uma água residuária, denominada rejeito (ou concentrado ou salmoura), que possui alta concentração de sais, o que torna seu descarte um problema ambiental (Soares et al., 2006).

Nesse contexto e como alternativa produtiva para a utilização de águas salobras subterrâneas e também para destinação nobre do rejeito de sua dessalinização, tem-se apontado para estudos de viabilidade técnica com cultivos no sistema hidropônico (Soares et al., 2007). A técnica do cultivo hidropônico em NFT (técnica do fluxo laminar de nutrientes) apresenta vantagens como: eficiência no uso da água e nutrientes; melhor aproveitamento da área; elevadas produtividades e possibilidade de um controle maior no descarte do seu rejeito, minimizando os efeitos negativos sobre o meio ambiente.

Nos sistemas de cultivo em solo o potencial mátrico tem grande contribuição na diminuição do potencial total da água (Cardoso \& Klar, 2009), dificultando a absorção de águas pelas plantas. Esta diminuição é ainda maior quando o potencial mátrico soma-se ao potencial osmótico das águas salobras. Com isto, Soares et al. (2007) levantaram a hipótese de que, na produção hidropônica tipo NFT o potencial mátrico pode ser anulado, aumentando o potencial total da água e, como consequência, reduzindo os efeitos negativos do uso de águas salobras. Paulus (2008) também trabalhou com essa hipótese, porém, ambos os estudos foram desenvolvidos em Piracicaba, SP, fora da realidade do semiárido; além disso, buscou-se produzir artificialmente a salinidade das águas, mediante a adição de $\mathrm{NaCl}$. Este é um ponto importante pois, a despeito da maioria das águas subterrâneas do semiárido ser do tipo cloretado sódica (Silva Júnior et al.; 1999), outros íons nutrientes às culturas são encontrados nessas águas em proporções variadas, o que se pode constituir em uma vantagem comparativa, considerando-se concentrações iso-osmóticas.

Escolheu-se a cultura da alface por apresentar precocidade em seu ciclo produtivo (50 a 70 dias), por ser moderadamente sensível a salinidade em solo (Maas \& Hoffman, 1977) e, sobretudo, por se tratar de uma hortaliça de grande importância socioeconômica e a mais cultivada em sistema hidropônico NFT no Brasil (Furlani et al., 1999).

Buscou-se selecionar, para o presente estudo, um local abastecido de água subterrânea salobra, que possuísse equipamento de osmose reversa e cujo rejeito fosse inadequadamente descartado. Neste sentido, selecionou-se o Distrito de Poço do Boi, dentro do município de Ibimirim, região semiárida de Pernambuco, após consulta ao sistema de cadastro de poços do Serviço Geológico do Brasil (CPRM, 2006).

Ibimirim possui o maior açude do estado e a agricultura irrigada é a atividade que mais demanda água desse açude; entretanto, a eficiência de aplicação de água é baixa, resultado da capacitação incipiente dos irrigantes, do predomínio da irrigação por superfície e também reflexo da ausência ou má difusão de tecnologias adequadas ao convívio com as estiagens prolongadas. Segundo Freire et al. (2003), a ocorrência de solos salinizados devido ao manejo incorreto da irrigação é comum em Ibimirim.

O aproveitamento de águas subterrâneas salobras na hidroponia pode abrir uma nova perspectiva para a agricultura do Semiárido brasileiro colaborando, inclusive, com uma segurança ambiental maior, uso eficiente da água, aumento da geração de renda aos produtores, aumento da qualidade de vida e consequente fixação do homem no campo (Soares et al., 2007; Paulus, 2008).

O objetivo do presente trabalho foi avaliar o crescimento e a produção de duas variedades de alface (cultivar crespa 'Vera' e variedade lisa 'AF-1743') nas condições semiáridas de Ibimirim (Pernambuco) quando cultivadas em sistema hidropônico NFT sob diferentes níveis de salinidade proporcionados pela água salobra de um poço tubular profundo e também pelo rejeito da sua dessalinização.

\section{MATERIAL E MÉTODOS}

\section{Localização da área experimental}

O experimento foi conduzido no período de 10 de agosto a 26 de setembro de 2008 no Distrito Poço do Boi, Município de Ibimirim (Pernambuco), situado nas coordenadas geográficas $8^{\circ} 32$ ' 15 " de latitude Sul, $37^{\circ} 41^{\prime} 30^{\prime}$ ' de longitude Oeste e a uma altitude $431 \mathrm{~m}$. O clima é do tipo B'Swh', semiárido muito quente, tipo estepe (classificação de Köppen), com precipitação pluvial e temperatura média anual de $420 \mathrm{~mm}$ e $25^{\circ} \mathrm{C}$, respectivamente. Os meses mais quentes do ano possuem registros máximos de 
temperatura entre 35 e $40{ }^{\circ} \mathrm{C}$, sendo eles os meses de novembro e dezembro, enquanto a temperatura mínima, aproximadamente $23{ }^{\circ} \mathrm{C}$, ocorre nos meses de julho e agosto (LAMEPE, 2008).

\section{Estrutura experimental}

A estrutura de experimentação foi montada em uma casa de vegetação, que possuía $7 \mathrm{~m}$ de largura, $24 \mathrm{~m}$ de comprimento, $4 \mathrm{~m}$ de pé direito e $5,5 \mathrm{~m}$ de altura, com cobertura em arco. As laterais foram teladas e possuíam rodapé de $20 \mathrm{~cm}$ em alvenaria. A cobertura do ambiente é em filme agrícola de polietileno, com $150 \mu \mathrm{m}$ de espessura, possuindo tratamento antiultravioleta. O piso foi revestido com manta geotêxtil ('bidim'), com o objetivo de melhorar as condições fitossanitárias e minimizar os efeitos da poeira sobre o sistema de bombeamento.

A casa de vegetação foi dividida em quatro blocos para que os efeitos das variações locais pudessem ser considerados. Cada bloco contava com 12 unidades experimentais.

Construíram-se 48 bancadas hidropônicas em sistema NFT (técnica do fluxo laminar de nutrientes), cada qual representando uma parcela experimental, semelhante à descrita por Soares et al. (2009). Cada bancada tinha um reservatório plástico individual com capacidade para $60 \mathrm{~L}$; um abastecedor automático para reposição da lâmina evapotranspirada; uma eletrobomba de circulação; um perfil hidropônico feito em polipropileno com aditivo antiultravioleta com diâmetro de $75 \mathrm{~mm}$, comprimento de $3,0 \mathrm{~m}$ e orifícios com $2,5 \mathrm{~cm}$ de raio espaçados em $0,25 \mathrm{~m}$.

\section{Tratamentos}

Duas variedades de alface foram avaliadas: a 'Vera', uma cultivar do tipo crespa, e a AF-1743, variedade lisa.

Avaliaram-se seis níveis de salinidade da água, com condutividades elétricas (CEa) de 0,2;1,2;2,2;3,2;4,2 e $5,2 \mathrm{dS} \mathrm{m}^{-1}$. O tratamento $\mathrm{CEa} 0,2 \mathrm{dS} \mathrm{m}^{-1}$ foi considerado o tratamento controle. Esses níveis foram obtidos com misturas a partir de quatro tipos de água, quais sejam: água subterrânea salobra, obtida de poço tubular profundo $\left(2,44 \mathrm{dS} \mathrm{m}^{-1}\right)$ (Tabela 1); água dessalinizada, resultante da dessalinização da água do poço pelo processo da osmose reversa $\left(0,05 \mathrm{dS} \mathrm{m}^{-1}\right)$; rejeito da dessalinização $\left(4,65 \mathrm{dS} \mathrm{m}^{-1}\right)$ e rejeito II $\left(7,80 \mathrm{dS} \mathrm{m}^{-1}\right)$, obtido após dessalinização do primeiro rejeito. Essas águas foram usadas tanto para o preparo da solução nutritiva quanto para a reposição do consumo hídrico diário.

As concentrações dos nutrientes para o preparo da solução nutritiva foram baseadas nas concentrações indicadas por Furlani et al. (1999) para o cultivo de alface, sendo invariá- veis para todos os níveis de água salobra. Realizaram-se correções do pH das águas no momento de seu preparo, antes da adição dos fertilizantes. Correções do $\mathrm{pH}$ da solução nutritiva, mediante adição de $\mathrm{KOH}$ ou $\mathrm{HNO}_{3}$, foram feitas sempre que se extrapolavam os limites de 5 e 7 .

O delineamento experimental utilizado foi o inteiramente aleatorizado em blocos com seis níveis de salinidade da água em interação com as duas variedades, totalizando 12 tratamentos em quatro repetições. Em cada bancada hidropônica foram cultivadas as duas variedades, as quais foram dispostas de maneira alternada, nos orifícios. Das oito plantas cultivadas no perfil apenas as quatro centrais foram consideradas úteis.

Cada evento de irrigação durava 15 min e a programação diária foi executada com auxílio de um temporizador (Pilau et al., 2002). Das 7 h da manhã às 18 h o temporizador acionava o sistema a cada $15 \mathrm{~min}$, permanecendo ligado durante $15 \mathrm{~min}$; no período das 18 às $7 \mathrm{~h}$ da manhã o sistema foi programado para promover um evento de irrigação por hora.

Diariamente se registravam as temperaturas máxima e mínima e a umidade relativa do ar para um período de $24 \mathrm{~h}$ utilizando-se termohigrômetro digital. O aparelho foi protegido em um abrigo e instalado no centro da casa de vegetação a uma altura de $1,50 \mathrm{~m}$ em relação à superfície do solo.

A solução nutritiva foi monitorada diariamente registrando-se os valores de $\mathrm{pH}$, condutividade elétrica (CEsol) e temperatura. $\mathrm{O} \mathrm{pH}$ e a CEsol foram medidos uma vez por dia, sempre pela manhã, para que os valores medidos representassem as variações de um período de $24 \mathrm{~h}$. A temperatura da solução foi medida às $15 \mathrm{~h}$ em um reservatório de uma bancada localizada no centro da casa de vegetação. Escolheuse este horário com base em um acompanhamento prévio da temperatura entre 6 e $18 \mathrm{~h}$ durante seis dias, buscando-se o momento em que a solução atingia sua maior temperatura.

\section{Análise}

Para avaliação do crescimento e rendimento das variedades de alface cultivada, analisaram-se as seguintes variáveis: número de folhas por planta (NF), diâmetro de cabeça (DC), e massa de matéria fresca da parte aérea (MFPA), determinadas no dia da colheita (47 dias após a semeadura). A massa de matéria seca da parte aérea (MSPA) foi outra variável analisada, sendo determinada após secagem em estufa a $65^{\circ} \mathrm{C}$ até atingir massa constante. As variáveis MFPA e MSPA foram determinadas com o auxílio de uma balança de precisão $(0,01 \mathrm{~g})$.

O teor de água na parte aérea da planta (U) foi avaliado através da Eq. 1.

Tabela 1. Composição química da água salobra do poço tubular profundo

\begin{tabular}{|c|c|c|c|c|c|c|c|c|c|}
\hline \multirow{4}{*}{ pH } & \multicolumn{9}{|c|}{ Composição química da água } \\
\hline & \multicolumn{4}{|c|}{ Cátions } & \multicolumn{5}{|c|}{ Ânions } \\
\hline & $\mathrm{Ca}^{++}$ & $\mathrm{Mg}^{++}$ & $\mathbf{K}^{+}$ & $\mathrm{Na}^{+}$ & $\mathrm{Cl}^{-}$ & $\mathrm{CO}_{3}^{-}$ & $\mathrm{HCO}_{3}^{-}$ & $\mathrm{SO}_{4}^{-}$ & RAS \\
\hline & \multicolumn{8}{|c|}{$\left(\mathrm{mg} \mathrm{L}^{-1}\right)$} & $\left(\mathrm{mmol}_{\mathrm{c}} \mathrm{L}^{-1}\right)^{1 / 2}$ \\
\hline 7,40 & 74,19 & 71,86 & 2,73 & 179,79 & 383,72 & 52,85 & 361,24 & 133,40 & 3,56 \\
\hline
\end{tabular}

A água do poço apresenta salinidade sazonal. A amostra avaliada para a presente caracterização química apresentava salinidade de $1,7 \mathrm{dS} \mathrm{m}^{-1}$ 


$$
\mathrm{U}(\%)=\left(\frac{\mathrm{MFPA}-\mathrm{MSPA}}{\mathrm{MFPA}}\right) \times 100
$$

Os dados foram submetidos à análise de variância utilizando-se o programa estatístico SAS. As variáveis foram avaliadas pelo teste $\mathrm{F}$, sendo que as variáveis com efeitos significativos por esse teste foram submetidas à análise de regressão para o fator nível de salinidade da água. As variedades foram submetidas à comparação de média utilizandose o teste de Tukey a nível de $5 \%$ de probabilidade.

\section{RESULTADOS E DISCUSSÃO}

\section{Monitoramento climático e da solução nutritiva}

As altas temperaturas são características da região em que o experimento foi conduzido. As temperaturas médias diárias do ar no interior da casa de vegetação registradas durante o período de estudo, variaram de 18,1 a $41,7{ }^{\circ} \mathrm{C}$ para as temperaturas mínimas e máximas, respectivamente, tendo as temperaturas mínimas (base de $24 \mathrm{~h}$ ) variado de 15,8 a $28,1{ }^{\circ} \mathrm{C}$ e as máximas (base de $24 \mathrm{~h}$ ) de 37,9 a $46,9{ }^{\circ} \mathrm{C}$. Em relação à umidade relativa do ar as médias no período de cultivo variaram de 19,4 a $85,7 \%$.

Os valores registrados de temperatura do ar ultrapassaram as recomendações $\left(15 \mathrm{a} 25^{\circ} \mathrm{C}\right.$ ) para alface (Martinez, 2006), à semelhança da umidade relativa do ar cujos valores registrados estiveram acima do recomendado como faixa ideal, qual seja, de 60 a 80\% (Martinez, 2006). As temperaturas da solução nutritiva tomadas às $15 \mathrm{~h}$ variaram entre 31,5 e $36^{\circ} \mathrm{C}$, sendo que no ciclo a média da temperatura neste horário foi de $33,3{ }^{\circ} \mathrm{C}$. Registrou-se, portanto, que a temperatura da solução chegou a ultrapassar o limite indicado por Alberoni (1998), qual seja, $30^{\circ} \mathrm{C}$. O mesmo autor recomenda, como ideais as temperaturas na faixa de 18 a $24{ }^{\circ} \mathrm{C}$ para períodos quentes e de 10 a $16{ }^{\circ} \mathrm{C}$ para períodos frios. Esta não idealidade nas condições climáticas pode ter tornado os efeitos da salinidade dos tratamentos mais severos.

$\mathrm{O} \mathrm{pH}$ da solução foi ajustado para a faixa entre 5 e 7 , valores esses dentro da faixa de tolerância das plantas $(4,5$ a 7,5) (Furlani et al., 1999), no mesmo dia do transplantio, porém, variações foram registradas entre os diferentes níveis de salinidade no dia seguinte (1 DAT). Essas variações se caracterizaram com elevação do $\mathrm{pH}$ da solução para valores próximos de 8, exceto para o tratamento controle (CEa 0,2), para o qual se registrou pH abaixo de 7 (Figura 1A).

$\mathrm{O}$ pH da solução ao longo do ciclo (Figura 1A) também variou entre os níveis de salinidade; entretanto, ajustes de $\mathrm{pH}$ foram realizados com o propósito de mantê-lo dentro de uma faixa ideal. Como as águas utilizadas para a reposição do volume evapotranspirado também foram salobras e fornecidas sem ajuste prévio de $\mathrm{pH}$, a solução nutritiva sempre retornava a uma faixa mais alcalina, registrando valores de $\mathrm{pH}$ de até 8,5.

A presença de carbonatos e bicarbonatos nas águas do presente estudo (Tabela 1) explica os elevados valores de $\mathrm{pH}$ e a dificuldade de mantê-lo dentro da faixa ideal. Segundo Resh (2001), a presença desses ânions na água implica em tamponamento da solução preparada com tendência à manutenção de valores elevados de $\mathrm{pH}$. Esta observação reforça a necessidade de tratamento prévio do $\mathrm{pH}$ da água subterrânea local e do rejeito do processo de dessalinização, mediante neutralização do carbonato e bicarbonato, para hidroponia comercial.

$\mathrm{O}$ pH da solução dentro do tratamento controle apresentou variações que não saíram da faixa ideal, exceto ao final do ciclo (15 a 22 DAT) (Figura 1A).

Durante o experimento não se procurou repor os nutrientes em virtude da alta disponibilidade de solução nutritiva por planta $(5,5 \mathrm{~L})$. Por outro lado, foram registrados, conforme previsto, aumentos nos níveis de salinidade da solução nutritiva ao longo do ciclo de cultivo (Figura 1B), com exceção do tratamento controle, o que pode ser explicado pelo manejo dado à reposição do volume evapotranspirado. Neste experimento, o reabastecimento de água ao reservatório era feito com água salobra com mesma concentração da água utilizada no preparo da solução. Desta forma, ocorreu um acúmulo contínuo de sais na solução, contribuindo para o aumento da CEsol, já para o tratamento controle a reposição de água foi feita com água dessalinizada, portanto, não houve acréscimo extra de sais nesse tratamento o que ocorreu foi o consumo natural de nutrientes pelas plantas e, como consequência, a diminuição da salinidade.

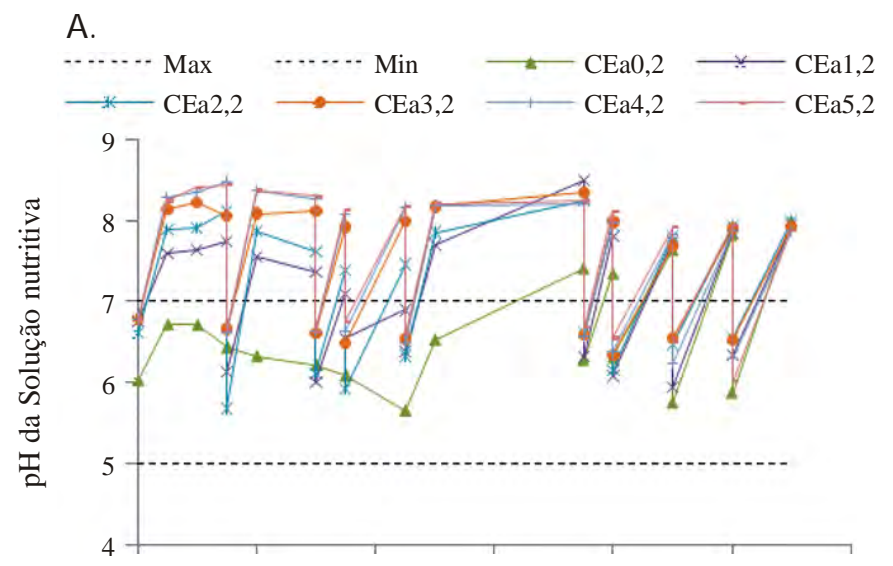

B.

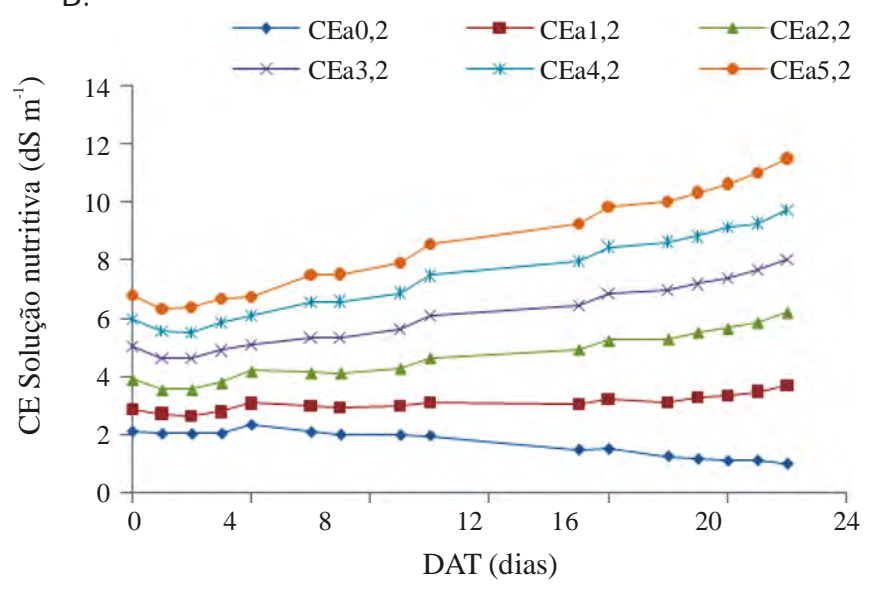

Figura 1. Valores médios do $\mathrm{pH}$ (A) e da condutividade elétrica (CE) (B) da solução nutritiva ao longo do ciclo de cultivo para as diferentes águas salobras testadas 


\section{Crescimento e rendimento da alface cultivada em águas salobras}

Verificou-se, de acordo com a análise de variância (Tabela 2), efeito do bloco sobre o teor de água na parte aérea da planta ao nível de 5\% de significância. Para a MFPA, o efeito do bloco foi significativo apenas a $10 \%$ de probabilidade, ainda assim, esses resultados demonstram a importância do controle local em blocos. Em relação aos fatores de interesse, quais sejam, variedades de alface e níveis de salinidade, foram registrados efeitos altamente significativos sobre todas as variáveis de crescimento e rendimento. Não ocorreu interação entre fatores ao nível de $5 \%$ de probabilidade.

Tabela 2. Resultado da análise de variância para as variáveis de crescimento da alface avaliadas no experimento

\begin{tabular}{ccrrrrr}
\hline $\begin{array}{c}\text { Causa de } \\
\text { variação }\end{array}$ & GL & \multicolumn{1}{c}{$\mathbf{N F}$} & \multicolumn{1}{c}{$\mathbf{D C}$} & \multicolumn{1}{c}{ MFPA } & \multicolumn{1}{c}{ MSPA } & $\mathbf{U}$ \\
\cline { 4 - 7 } & & \multicolumn{5}{c}{$\mathbf{P r}>\mathbf{F}$} \\
Bloco & 3 & 0,2578 & 0,4278 & 0,0726 & 0,2351 & 0,0291 \\
Variedade & 1 & $<0,0001$ & $<0,0001$ & $<0,0001$ & $<0,0001$ & 0,8368 \\
CEa & 5 & $<0,0001$ & $<0,0001$ & $<0,0001$ & $<0,0001$ & $<0,0001$ \\
Variedade*CEa & 5 & 0,0515 & 0,0925 & 0,6925 & 0,7573 & 0,5043 \\
\hline
\end{tabular}

NF - número de folha; DC - diâmetro de cabeça; MFPA - massa de matéria fresca da parte aérea; MSPA - massa de matéria fresca da parte aérea e U - teor de água

A análise do desdobramento das variedades dentro de cada nível de salinidade indicou diferenças estatísticas entre as duas variedades estudadas, tanto sob condições de baixa salinidade quanto sob alta salinidade, exceto para DC às baixas salinidades e U para todos os níveis (Tabela 3). Já o desdobramento dos níveis de salinidade dentro de cada variedade revelou efeito altamente significativo (Tabela 4).

Tabela 3. Resultado do desdobramento para as variedades de alface dentro de cada nível de salinidade da água (CEa)

\begin{tabular}{ccccccc}
\hline \multirow{2}{*}{ CEa } & \multirow{2}{*}{ GL } & NF & DC & MFPA & MSPA & U \\
\cline { 4 - 7 } & & \multicolumn{5}{c}{ Pr $>$ F } \\
0,2 & 1 & $<0,0001$ & 0,1872 & 0,0004 & 0,0002 & 0,4802 \\
1,2 & 1 & $<0,0001$ & 0,2341 & 0,0364 & 0,0255 & 0,7342 \\
2,2 & 1 & $<0,0001$ & 0,3527 & 0,0240 & 0,0111 & 0,8537 \\
3,2 & 1 & $<0,0001$ & 0,0515 & 0,1028 & 0,0361 & 0,4451 \\
4,2 & 1 & $<0,0001$ & 0,0001 & 0,0207 & 0,0069 & 0,2374 \\
5,2 & 1 & $<0,0001$ & 0,0005 & 0,0500 & 0,0147 & 0,1957 \\
\hline
\end{tabular}

NF - número de folha; DC - diâmetro de cabeça; MFPA - massa de matéria fresca da parte aérea; MSPA - massa de matéria fresca da parte aérea e U - teor de água

Tabela 4. Resultado do desdobramento para os níveis de salinidade dentro de cada variedade de alface

\begin{tabular}{ccccccc}
\hline $\begin{array}{c}\text { Causa de } \\
\text { variação }\end{array}$ & GL & NF & DC & MFPA & MSPA & U \\
\cline { 2 - 7 } AF-1743 & 5 & $<0,0001$ & $<0,0001$ & $<0,0001$ & $<0,0001$ & $<0,0001$ \\
Vera & 5 & $<0,0001$ & $<0,0001$ & $<0,0001$ & $<0,0001$ & $<0,0001$ \\
\hline
\end{tabular}

NF - número de folha; DC - diâmetro de cabeça; MFPA - massa de matéria fresca da parte aérea; MSPA - massa de matéria fresca da parte aérea e U - teor de água

Ao se fazer o teste de comparação de médias, confirmouse a diferença entre as variedades, registrando-se maior crescimento e maior produção absoluta para a variedade lisa 'AF-1743' (Tabela 5).
Tabela 5. Resultado da comparação de média pelo teste Tukey a nível de $5 \%$ de probabilidade para as variáveis de crescimento e rendimento das variedades cultivadas

\begin{tabular}{|c|c|c|c|c|c|}
\hline \multirow{2}{*}{ Variedade } & \multirow{2}{*}{ NF } & $D C$ & MFPA & MSPA & \multirow{2}{*}{$\begin{array}{c}\mathbf{U} \\
\%\end{array}$} \\
\hline & & $\mathrm{cm}$ & \multicolumn{2}{|c|}{ g planta-1 } & \\
\hline AF-1743 & $41,40 a$ & $38,75 a$ & 308,17 a & $17,74 a$ & 93,87 a \\
\hline Vera & $21,15 \mathrm{~b}$ & $34,52 \mathrm{~b}$ & 244,78 b & $13,74 \mathrm{~b}$ & $93,85 a$ \\
\hline D.M.S. & 1,46 & 1,54 & 21,60 & 1,18 & 0,21 \\
\hline
\end{tabular}

Médias seguidas de letras iguais na coluna não diferem estatisticamente.

D.M.S. - diferença mínima significativa; NF - número de folha; DC - diâmetro de cabeça; MFPA massa de matéria fresca da parte aérea; MSPA - massa de matéria fresca da parte aérea e U teor de água

A análise de regressão aplicada de forma conjunta aos dados de ambas as variedades, mostrou que todas as variáveis sofreram redução linear em função do aumento da salinidade da água usada. À exceção da variável NF, foram registrados coeficientes de determinação superiores a 60\%, o que indica que a maior parte das variações encontradas pode ser descrita através dos modelos propostos pela análise de regressão (Tabela 6).

Tabela 6. Resultado da análise de regressão aplicada às variáveis analisadas em função da sal inidade (análise conjunta de 'Vera' e 'AF-1743')

\begin{tabular}{ccc} 
Variável & Equação & $\mathbf{R}^{\mathbf{2}}$ \\
NF & $\mathrm{NF}=-2,718 \mathrm{CEa} *+38,609 * *$ & 0,164 \\
DC & $\mathrm{DC}=-3,748 \mathrm{CEa} * *+46,756 * *$ & 0,749 \\
MFPA & $\mathrm{MFPA}=-80,877 \mathrm{CEa} * *+494,844 * *$ & 0,866 \\
MSPA & $\mathrm{MSPA}=-3,630 \mathrm{CEa} *+25,545 * *$ & 0,785 \\
U & $\mathrm{U}=-0,499 \mathrm{CEa} *+95,204 * *$ & 0,837 \\
\hline
\end{tabular}

** representa significância a $1 \%$ de probabilidade; análise de dados com repetição

NF - número de folha; DC - diâmetro de cabeça; MFPA - massa de matéria fresca da parte aérea; MSPA - massa de matéria fresca da parte aérea e U - teor de água

Avaliando-se as respostas gráficas das análises de regressão aplicadas a cada variedade de alface (Figura 2), pode-se afirmar que, de maneira geral, os coeficientes de determinação estiveram em uma mesma faixa de valor para as duas variedades. Ainda que diferenças em termos absolutos tenham sido registradas para as variedades ao se analisar os decréscimos percentuais mediante as relações entre o coeficiente angular e o linear dos modelos de regressão, obtiveram-se reduções equivalentes entre ambas as variedades no domínio dos valores de salinidade estudados. O incremento unitário na salinidade da água apresentou diferenças de no máximo 2,76\% $\left(\mathrm{dS} \mathrm{m}^{-1}\right)^{-1}$ (Tabela 7).

Empregando-se o mesmo procedimento de cálculo da redução percentual por acréscimo unitário na salinidade da água aos dados apresentados por Paulus (2008) observouse que a autora obteve menores taxas de redução quando comparadas com as encontradas no presente trabalho. Por exemplo, para matéria fresca da parte aérea os dados da autora permitem estimar uma redução de 7,81\% $\left(\mathrm{dS} \mathrm{m}^{-1}\right)^{-1}$ enquanto no presente trabalho esta redução foi de 17,06 e $15,74 \%\left(\mathrm{dS} \mathrm{m}^{-1}\right)^{-1}$ para as variedades 'Vera' e 'AF-1743', respectivamente. As maiores reduções encontradas no presente estudo (Tabela 7) podem ser atribuídas às condições climáticas sob as quais o experimento foi conduzido, mas também às diferenças entre as fontes de salinidade e entre 
A.

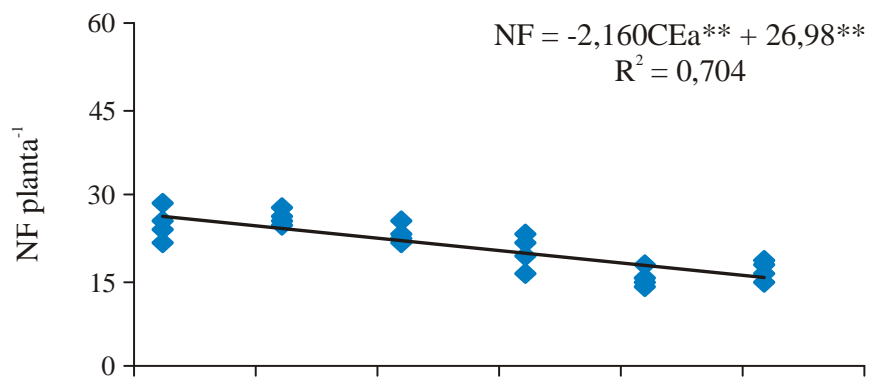

C.

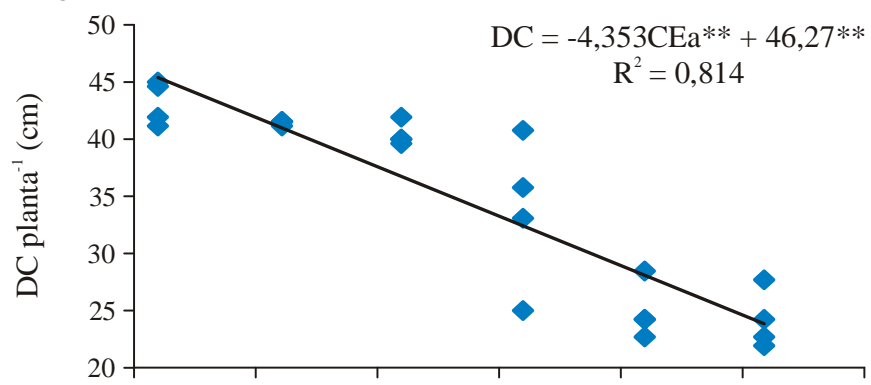

E.

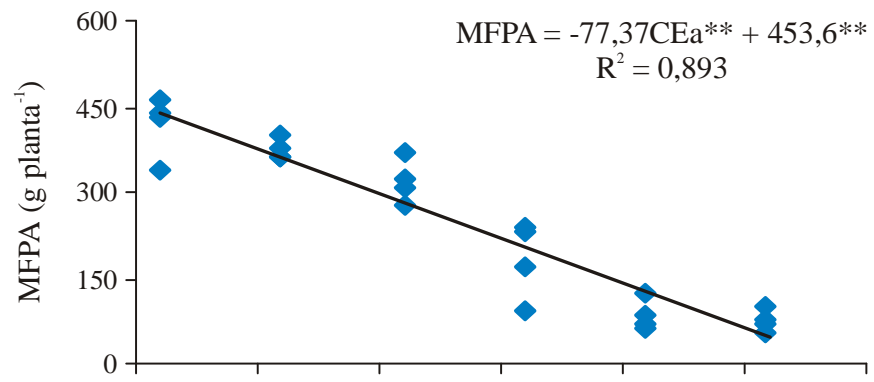

G.

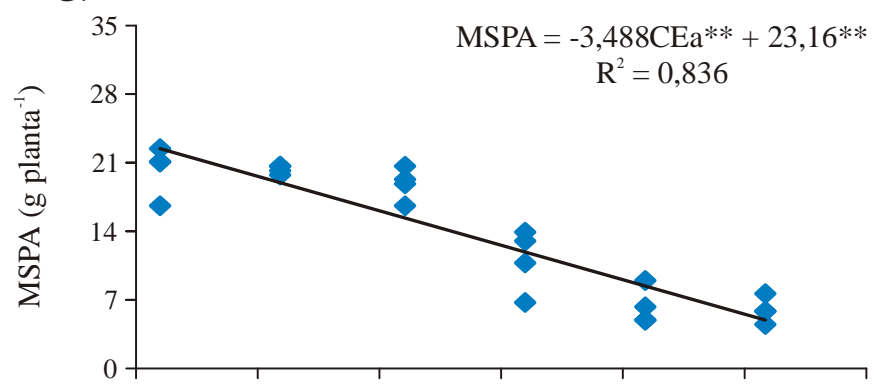

I.

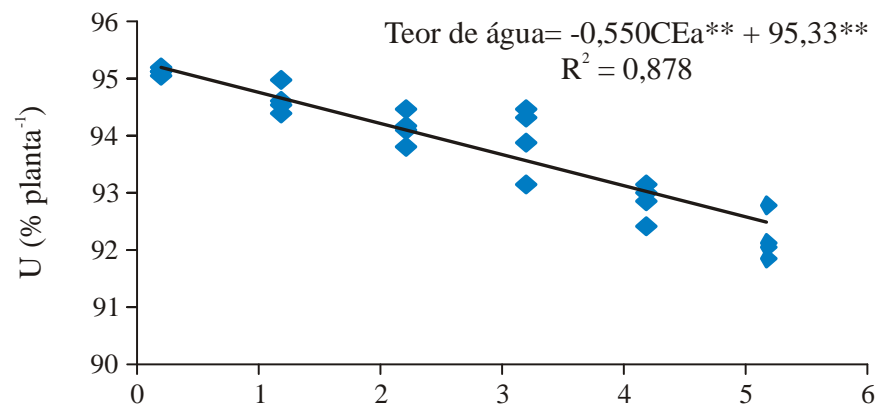

B.

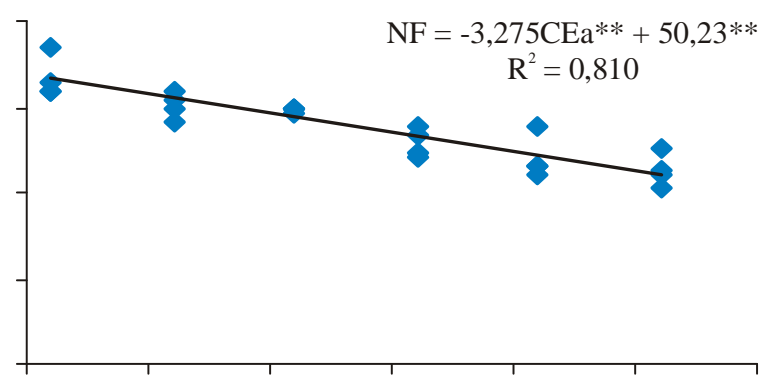

D.

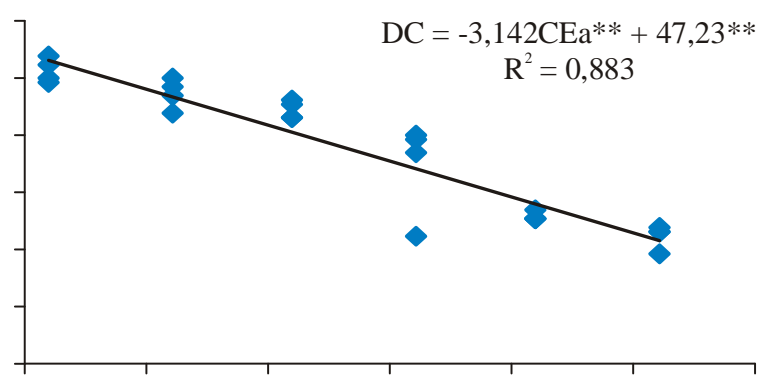

F.

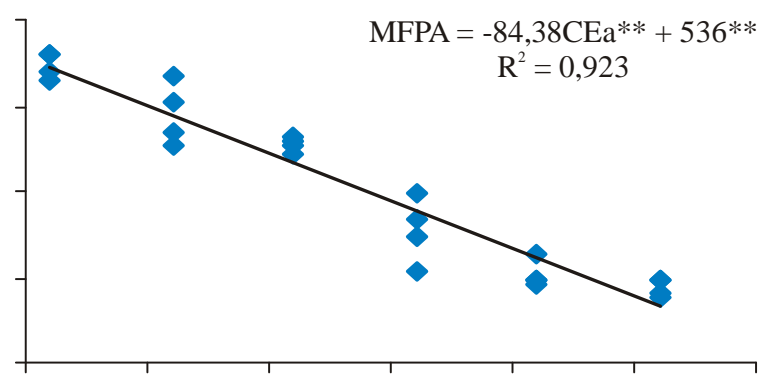

$\mathrm{H}$.

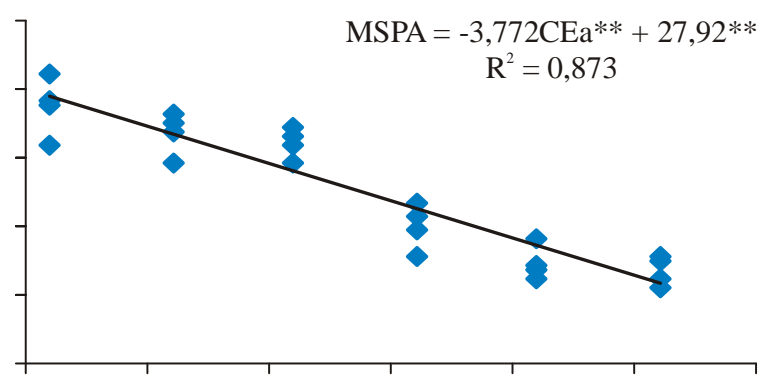

J.

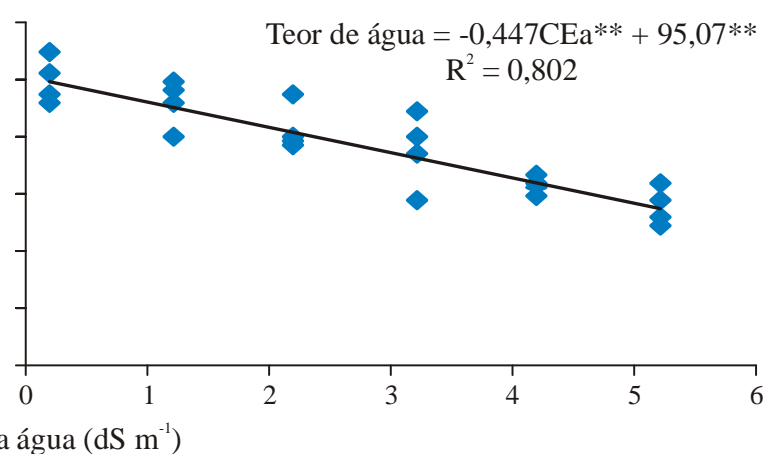

** representa significância a $1 \%$ de probabilidade

Figura 2. Número de folhas (NF) para as variedades 'Vera' (A) e 'AF-1743' (B); Diâmetro de cabeça (DC) para as variedades 'Vera' (C) e AF-1743 (D); Massa de matéria fresca da parte aérea (MFPA) para as variedades 'Vera'(E) e AF-1743 (F); Massa de matéria seca da parte aérea (MSPA) para as variedades 'Vera' (G) e AF-1743 (H) e teor de água na folha (U) para as variedades 'Vera' (I) e AF-1743 (J) em função da condutividade elétrica da água (CEa) 
Tabela 7. Valores de incremento percentual por acréscimo unitário na salinidade da água sobre as respostas de crescimento e produção das variedades crespa e lisa de alface

\begin{tabular}{|c|c|c|c|c|c|}
\hline Variável & Variedade & a & b & $\begin{array}{c}a / b \\
\%\left(d S m^{-1}\right)^{-1}\end{array}$ & $\frac{\Delta}{\%\left(\mathrm{dS} \mathrm{m}^{-1}\right)^{-1}}$ \\
\hline \multirow{2}{*}{$\mathrm{NF}$} & 'Vera' & $-2,16$ & 26,98 & $-8,01$ & \multirow{2}{*}{$-1,49$} \\
\hline & 'AF-1743' & $-3,275$ & 50,23 & $-6,52$ & \\
\hline \multirow{2}{*}{$D C$} & Vera' & $-4,353$ & 46,27 & $-9,41$ & \multirow{2}{*}{$-2,76$} \\
\hline & 'AF-1743' & $-3,142$ & 47,23 & $-6,65$ & \\
\hline \multirow{2}{*}{ MFPA } & 'Vera' & $-77,37$ & 453,60 & $-17,06$ & \multirow{2}{*}{$-1,31$} \\
\hline & 'AF-1743' & $-84,38$ & 536,00 & $-15,74$ & \\
\hline \multirow{2}{*}{ MSPA } & Vera' & $-3,488$ & 23,16 & $-15,06$ & \multirow{2}{*}{$-1,55$} \\
\hline & 'AF-1743' & $-3,772$ & 27,92 & $-13,51$ & \\
\hline \multirow{2}{*}{ U } & 'Vera' & $-0,55$ & 95,33 & $-0,58$ & \multirow{2}{*}{$-0,11$} \\
\hline & 'AF-1743' & $-0,447$ & 95,07 & $-0,47$ & \\
\hline
\end{tabular}

$\Delta$ - Diferença da redução percentual entre as variedades; NF - número de folha; DC - diâmetro de cabeça; MFPA - massa de matéria fresca da parte aérea; MSPA - massa de matéria fresca da parte aérea e U - teor de água

as cultivares. Segundo Sonneveld (1988), sob condições de clima mais ameno o efeito negativo da salinidade sobre as culturas é menor. Maas \& Hoffman (1977), por sua vez, reconhecem que, dentre inúmeros outros fatores, as diferenças genéticas entre variedades podem ser uma importante fonte de tolerância à salinidade dentro de uma mesma espécie.

Deve-se reiterar que o tipo de comparação acima conduzida entre os dados de Paulus (2008) e os do presente trabalho, somente é possível dentro de uma base comum de salinidade. Em ambos os casos, tratou-se de salinidade da água (e não da solução nutritiva), com valores na unidade $\mathrm{dS} \mathrm{m} \mathrm{m}^{-1}$. A comparação dos resultados obtidos com aqueles apresentados por Paulus (2008) é apropriada já que nos dois estudos a água salobra foi usada em todo o processo produtivo da hidroponia.

Em período anterior ao experimento (março de 2008), a salinidade da água subterrânea foi avaliada em $1,71 \mathrm{dS} \mathrm{m}^{-1}$. Durante o experimento (setembro de 2008), a salinidade foi medida em $2,44 \mathrm{dS} \mathrm{m}^{-1}$. A salinidade do rejeito da dessalinização também acompanhou essa sazonalidade sendo, normalmente, o dobro da salinidade do poço. Considerando as produções relativas à produção do tratamento controle (condição não salina), a água do poço permitiu uma produção de $63 \%$ para ambas as variedades; esta mesma fonte permitiria produções relativas de $75 \%$ com a salinidade da água de $1,71 \mathrm{dS} \mathrm{m}^{-1}$ (Figura 3A e B).

Por sua vez, o aproveitamento do rejeito com salinidade de $4,65 \mathrm{dS} \mathrm{m}^{-1}$, possibilitaria produções relativas de apenas 21 e $27 \%$ para as variedades 'Vera' e 'AF 1743', respectivamente (Figura 3A e B); neste caso, a inviabilidade econômica poderia ser também reforçada pela presença de sintomas de clorose generalizada. Mesmo para um rejeito com salinidade de 3,2 $\mathrm{dS} \mathrm{m}^{-1}$, proveniente da dessalinização de uma água com salinidade de $1,71 \mathrm{dS} \mathrm{m}^{-1}$, a produção seria baixa e inferior a $50 \%$.

\section{Sintomatologia da alface produzida}

Analisando a cronologia do aspecto visual da alface, observou-se que não houve efeito sobre a coloração das plan-
A.

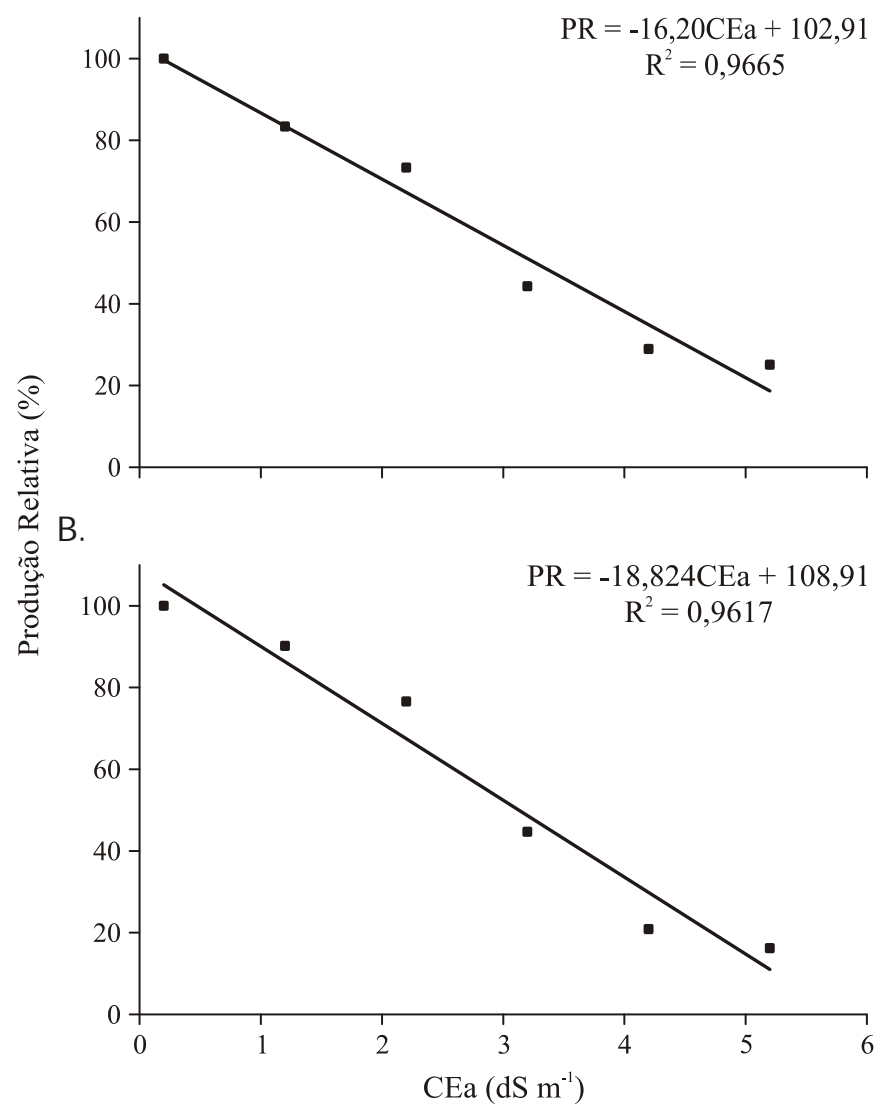

Figura 3. Produção relativa para as variedades 'Vera' (A) e AF-1743 (B) em função da condutividade elétrica da água (CEa)

tas, de ambas as variedades, submetidas ao tratamento controle e às salinidades da água de 1,2 e 2,2 dS m ${ }^{-1}$, porém, as plantas submetidas aos níveis mais elevados de salinidade da água $\left(3,2 ; 4,2\right.$ e 5,2 $\left.\mathrm{dS} \mathrm{m}^{-1}\right)$ apresentaram sintomas de clorose generalizada (Tabela 8). Outro fato constatado foi que as plantas submetidas a essas salinidades mais elevadas apresentaram certa recuperação de sua coloração passando de uma escala mais intensa de clorose, no início do ciclo, para uma escala mais moderada, ao final, o que pode representar uma possível adaptação das plantas aos níveis de salinidade ao longo do ciclo de cultivo.

Notou-se, também, clorose intensa nas bordas foliares, sintoma este registrado apenas nas folhas mais velhas da variedade 'Vera' submetida aos tratamentos com salinidade mais elevada (Figura 4C). Este sintoma não foi observado na variedade 'AF-1743'.

Por outro lado, enquanto plantas da variedade 'Vera' não apresentaram queima das bordas foliares (tipburn), algumas plantas da variedade 'AF-1743' foram acometidas por este problema. Deve-se ressalvar, entretanto, que o referido sintoma foi visualizado apenas em algumas folhas de plantas aleatoriamente distribuídas entre tratamentos e entre plantas da mesma parcela, sem registro de uma relação direta com a salinidade (Figura 4B e D).

Por se tratar de uma desordem fisiológica relacionada à deficiência de cálcio e se considerando o reconhecido efeito dos sais no desequilíbrio nutricional, esperou-se encontrar 
Tabela 8. Resultado da análise visual de sintomas de clorose em folhas de alface das variedades 'Vera' (crespa) e 'AF-1743' (lisa) submetidas a salinidade da água

\begin{tabular}{|c|c|c|c|c|c|c|}
\hline Trat. & 0 DAT & 6 DAT & 8 DAT & 10 DAT & 18 DAT & 22 DAT \\
\hline CEa 0,2 & V & V & V & V & V & V \\
\hline CEa 0,2 & V & V & V & V & V & V \\
\hline CEa 0,2 & V & V & V & V & V & V \\
\hline CEa 0,2 & V & V & V & V & V & V \\
\hline CEa 1,2 & V & V & V & V & V & V \\
\hline CEa 1,2 & V & V & V & V & V & V \\
\hline CEa 1,2 & V & V & V & V & V & V \\
\hline CEa 1,2 & V & V & V & V & V & V \\
\hline CEa 2,2 & V & V & V & V & V & V \\
\hline CEa 2,2 & V & V & V & V & V & V \\
\hline CEa 2,2 & V & V & $C M$ & V & V & V \\
\hline CEa 2,2 & V & V & V & V & V & V \\
\hline CEa 3,2 & V & CM & CM & V & V & V \\
\hline CEa 3,2 & V & $\mathrm{CM}$ & $C M$ & V & V & V \\
\hline CEa 3,2 & V & $\mathrm{CM}$ & C & $\mathrm{CM}$ & CM & $\mathrm{CM}$ \\
\hline CEa 3,2 & V & $\mathrm{CM}$ & V & V & V & V \\
\hline CEa 4,2 & V & C & C & CM & $\mathrm{CM}$ & V \\
\hline CEa 4,2 & V & $\mathrm{CM}$ & C & $\mathrm{CM}$ & CM & $\mathrm{CM}$ \\
\hline CEa 4,2 & V & C & $C M$ & CM & CM & $\mathrm{CM}$ \\
\hline CEa 4,2 & V & C & C & CM & CM & $\mathrm{CM}$ \\
\hline CEa 5,2 & V & C & C & CM & CM & $\mathrm{CM}$ \\
\hline CEa 5,2 & V & $C$ & $C$ & $\mathrm{CM}$ & CM & CM \\
\hline CEa 5,2 & V & C & C & $\mathrm{CM}$ & $\mathrm{CM}$ & CM \\
\hline CEa 5,2 & V & C & C & CM & CM & CM \\
\hline
\end{tabular}

$\mathrm{V}$ - Verde normal; CM - Clorose moderada; C - Clorose
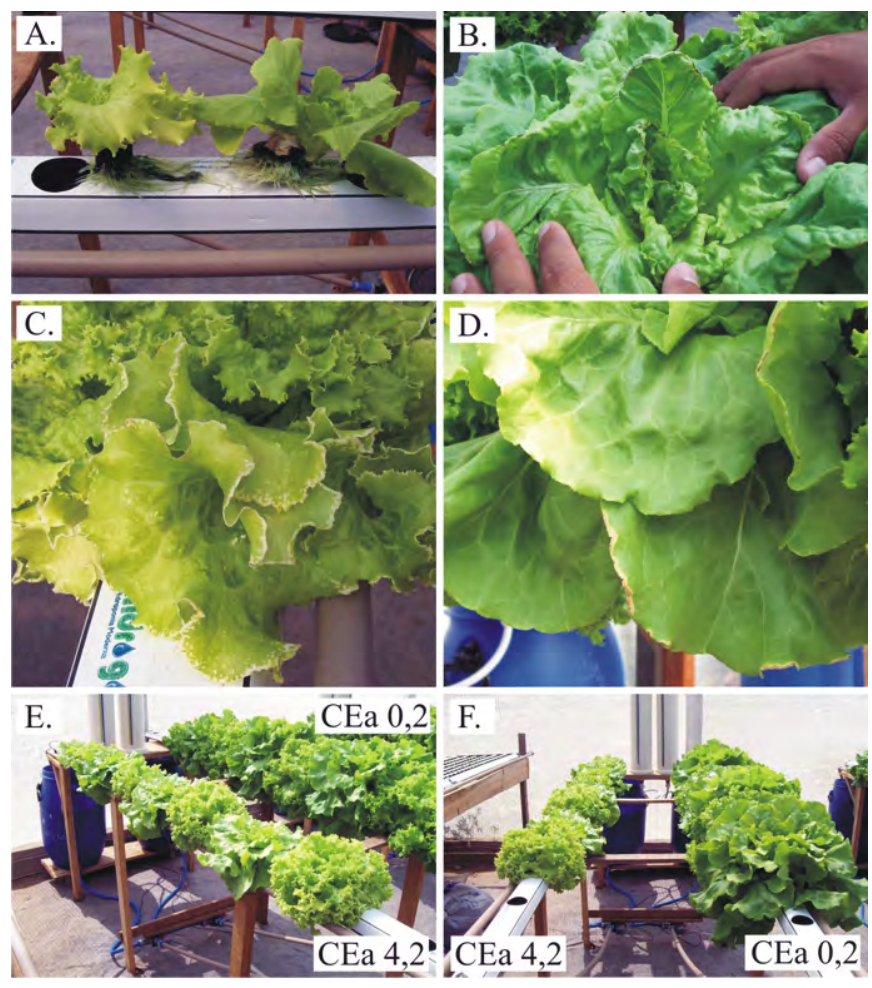

Figura 4. Raízes com deposição de sais precipitados (A); tip burn em 'AF-1743' (B); clorose intensa das bordas foliares na variedade 'Vera' (C); necrose das bordas das folhas mais velhas na variedade 'AF-1743' (D); contraste de tamanho entre plantas submetidas aos tratamentos CEa0,2 e CEa4,2 dS m-1 (E e F) mais plantas sintomáticas com "tipburn" sob os maiores níveis de salinidade, como relatam Pereira et al. (2005). Neste sentido, a distribuição aleatória do problema pode ser explicada pela presença de cálcio nas águas salobras, o que pode ter mitigado tal desordem fisiológica. A incidência de "tipburn" também pode estar relacionada com o destacado crescimento da variedade 'AF-1743'. Beninni et al. (2003) ressaltam que alguns autores têm verificado o aumento da incidência do "tipburn" em plantas com elevadas taxas de crescimento, fenômeno que pode ocorrer em função do aumento na demanda de cálcio e da insuficiente translocação para os locais de crescimento da planta.

As raízes das plantas de alface apresentaram deposição de sais (Figura 4A) devido à ocorrência de precipitados na solução nutritiva. Esta precipitação foi atribuída às interações dos ânions $\mathrm{CO}_{3}$ e $\mathrm{HCO}_{3}$, presentes na água de irrigação (Tabela 1), com os fertilizantes.

Outro sintoma observado neste caso, em ambas as variedades, foi o raquitismo, que acometeu as plantas submetidas aos níveis mais elevados de salinidade da solução nutritiva. As Figuras 4E e F mostram o contraste de tamanho entre as plantas submetidas à solução nutritiva preparada com água de 0,2 e 4,2 $\mathrm{dS} \mathrm{m}^{-1}$. Segundo Maas \& Hoffman (1977), existe um limiar de concentração de sal acima do qual as plantas começam a mostrar sinais de inibição de crescimento, descoloração foliar e perda de massa de matéria seca. Costa et al. (2001) por sua vez, dizem que essas alterações se relacionam, dentre outros fatores, à abertura estomática e ao aumento ou diminuição da área foliar, estando esses fatores intimamente ligados à eficiência fotossintética e, consequentemente, à produção de matéria pelas plantas.

\section{CONCLUSÕES}

1. Sob condições de salinidade provocada por águas de rejeito diluídas, a variedade de alface lisa 'AF-1743' teve maior crescimento e rendimento absolutos quando comparada com a cultivar de alface crespa 'Vera'.

2. Em termos de resposta relativa obtida como redução percentual do crescimento e rendimento por acréscimo unitário na salinidade, as reduções registradas para ambas as variedades foram equivalentes.

3. O uso de águas salobras, tanto para o preparo da solução nutritiva quanto para a reposição do consumo hídrico, resultou em reduções lineares de 17 e $15,7 \%\left(\mathrm{dS} \mathrm{m}^{-1}\right)^{-1}$ no rendimento das variedades 'Vera' e 'AF-1743', respectivamente.

4. A água subterrânea salobra apresentou viabilidade de uso para produção hidropônica da alface mas a água residuária de sua dessalinização proporcionou baixas produções e sintomas foliares que não justificariam seu aproveitamento comercial.

\section{AGRADECIMENTOS}

Os autores agradecem à Prefeitura Municipal de Ibimirim, pelo apoio e concessão da área do experimento; à 
SAKATA (João Totti Felix) pelo fornecimento de sementes; à TIGRE (Olacir Martins Luciano) pelo fornecimento de tubos e conexões; à Coordenadoria de Aperfeiçoamento de Pessoal de Nível Superior (CAPES), pela concessão da bolsa; ao Conselho Nacional de Desenvolvimento Científico e Tecnológico (CNPq), ao Instituto Nacional de Ciência e Tecnologia em Salinidade (INCTSal) e à Fundação de Amparo à Ciência e Tecnologia do Estado de Pernambuco (FACEPE) pelo financiamento do projeto.

\section{LITERATURA CITADA}

Alberoni, R. B. Hidroponia. São Paulo: Nobel, 1998. 102p.

Alencar, R. D.; Porto Filho, F. Q.; Medeiros, J. F. de; Holanda, J. S.; Porto, V. C. N.; Ferreira Neto, M. Crescimento de cultivares de melão amarelo irrigadas com água salina. Revista Brasileira de Engenharia Agrícola e Ambiental, v.7, n.2, p.221-226, 2003.

Beltran, J. M. Irrigation with saline water: Benefits and environmental impact. Agricultural Water Management, v.40, n.2, p.183-194, 1999.

Beninni, E. R. Y.; Takahashi, H. W.; Neves, C. S. V. J. Manejo do cálcio em alface de cultivo hidropônico. Horticultura Brasileira, v.21, n.4, p.605-610, 2003.

Brasil. Ministério da Saúde. Portaria n ${ }^{\circ}$ 1.469, Diário Oficial da União, Brasília. 29 de Dez de 2000.

Cardoso, G. G. G.; Klar, A. E. Potenciais de água no solo na produção de alface. Irriga, v.14, n.2, p.170-179, 2009.

Costa, A. M. B.; Melo, J. G.; Silva, F. M. Aspectos da salinização das águas do aqüífero cristalino no estado do Rio Grande do Norte, Nordeste do Brasil. Águas Subterrâneas, v.20, n.1, p.67-82, 2006.

Costa, P. C.; Didone, E. B.; Sesso, T. M.; Cañizares, K. A. L.; Goto, R. Condutividade elétrica da solução nutritiva e produção da alface em hidroponia. Scientia Agricola, v.58, n.3, p.595-597, 2001.

Costa, W. D. Problemática da água subterrânea no nordeste brasileiro. Revista Águas Subterrânea, v.14, p.25-42, 1995.

CPRM - Serviço Geológico do Brasil. Sistema de Informação de águas subterrâneas - SIAGAS. <http://siagas.cprm.gov.br/wellshow/indice.asp>. 08 Fev. 2006.

Freire, M. B. G. S.; Ruiz, H. A.; Ribeiro, M. R.; Feirrera, P. A.; Alvarez V. V. H.; Freire, F. J. Estimativa do risco de sodificação de solos de Pernambuco pelo uso de águas salinas. Revista Brasileira Engenharia Agrícola e Ambiental, v.7, n.2, p.227-232, 2003.

Furlani, P. R.; Silveira, L. C. P.; Bolonhezi, D.; Faquin, V. Cultivo hidropônico de plantas. Campinas: IAC, 1999. 52p. Boletim técnico, 180.
Garcia, G. O.; Martins Filho, S.; Reis, E. F.; Moraes, W. B.; Nazário, A. A. Alterações químicas de dois solos irrigados com água salina. Revista Ciência Agronômica, v.39, n.1, p.7-18, 2008.

LAMEPE - Laboratório de Meteorologia de Pernambuco. http:// www.itep.br/LAMEPE.asp. 15 Dez. 2008.

Maas, E. V.; Hoffman, G. J. Crop salt tolerance: Current assessment. Journal of Irrigation and Drainage Division ASCE, v.103, n.IR2, p.115-134, 1977.

Martinez, H. E. P. Manual prático de hidroponia. Viçosa: Aprenda Fácil, 2006. 271p.

Paulus, D. Produção, qualidade e parâmetros fisiológicos e bioquímicos de alface sob hidroponia com águas salinas. Piracicaba: ESALQ/USP, 2008. 105p. Tese Doutorado

Pereira, C.; Junqueira, A. M. R.; Oliveira, S. A. Balanço nutricional e incidência de queima de bordos em alface produzida em sistema hidropônico - NFT. Horticultura Brasileira, v.23, n.3, p.810-814, 2005.

Pilau, F. G.; Medeiros, S. L. P.; Manfron, P. A.; Bianchi, C.; Caron, B. O.; Bonnecarrère, R. Influência do intervalo entre irrigações na produção e nas variáveis fisiológicas da alface hidropônica. Revista Brasileira de Agrometeorologia, v.10, n.2, p.237-244, 2002.

Pinheiro, J. C. V.; Callado, S. M. G. Avaliação de desempenho dos dessalinizadores no Ceará. Revista Econômica do Nordeste, v.36, n.1, p.43-59, 2005.

Porto, E. R.; Amorim, M. C. C.; Silva Júnior, L. G. A. Uso do rejeito da dessalinização de água salobra para irrigação da ervasal (Atriplex nummularia). Revista Brasileira de Engenharia Agrícola e Ambiental, v.5, n.1, p.111-114, 2001.

Resh, H. M. Hydroponic food production: A definitive guidebook of soilless food growing methods. $6^{\text {th }}$. ed. Santa Barbara: Woodbridge Press Publishing Company, 2001. 567p.

Silva Júnior, L. G. A.; Gheyi, H. R.; Medeiros, J. F. de. Composição química de águas do cristalino do nordeste brasileiro. Revista Brasileira de Engenharia Agrícola e Ambiental, v.3, n.1, p.11-17, 1999.

Soares, T. M. ; Duarte, S. N.; Silva, E. F. F.; Melo, R. F.; Jorge, C. A.; Oliveira, A. S. Experimental structure for evaluation of saline water use in lettuce hydroponic production. Irriga, v.14, n.1, p.102-114. 2009.

Soares, T. M.; Silva, E. F. F.; Duarte, S. N.; Melo, R. F.; Jorge, C. A.; Bonfim-Silva, E. M. Produção de alface utilizando águas salinas em sistema hidropônico. Revista Irriga, v.12, n.2, p.235-248, 2007.

Soares, T. M.; Silva, I. J. O.; Duarte, S. N.; Silva, E. F. F. Destinação de águas residuárias provenientes de dessalinizadores por osmose reversa. Revista Brasileira de Engenharia Agrícola e Ambiental, v.10, n.3, p.730-737, 2006.

Sonneveld, C. The salt tolerance of greenhouse crops. Netherlands Journal of Agricultural Science, v.36, p.63-73, 1988. 